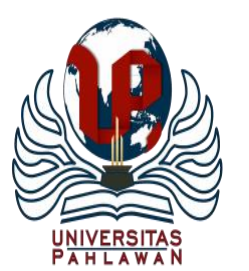

Jurnal Abdidas Volume 2 Nomor 5 Tahun 2021 Halaman 1251-1256

JURNAL ABDIDAS

http://abdidas.org/index.php/abdidas

\title{
Edukasi Terapi Back Massage Terhadap Penurunan Tinggi Fundus Uteri pada Kelas Ibu Hamil di Praktek Mandiri Bidan Marni Novera, Amd.Keb Padang
}

\author{
Titin Ifayanti $^{1 凶}$, Silfina Indriani $^{2}$ \\ Kebidanan, STIKes Alifah Padang, Indonesia ${ }^{1,2}$ \\ E-mail: titin.titinifayanti@yahoo.com ${ }^{1} \underline{\text { silfinaindriani1985@gmail.com }}^{2}$
}

\begin{abstract}
Abstrak
Pelayanan kesehatan bagi ibu postpartum perlu dilakukan guna mencapai kehidupan yang optimal baik ibu maupun bayinya, salah satu bentuk pelayanan untuk memaksimalkan kestabilan kondisi kesehatan mental ibu adalah dengan memberikan intervensi back massage sebagai upaya pencegahan terjadinya perdarahan pada ibu postpartum dan percepatan penurunan tinggi fundus uteri. Tujuan dari pengabdian masyarakat ini adalah untuk memberikan informasi kepada ibu nifas tentang back massage, serta membekali ibu dengan pengetahuan tentang back massage serta mengajarkan terapi ini kepada ibu untuk membantu mempercepat penurunan tinggi fundus uteri setelah persalinan. Kegiatan ini dilaksanakan di Praktek Mandiri Bidan Marni Novera, Amd.Keb Padang, pada 12 Juli 2021. Sasaran kegiatan adalah ibu nifas yang ada di Praktek Mandiri Bidan Marni Novera, Amd.Keb. Secara keseluruhan kegiatan terlaksana sesuai dengan waktu yang direncankan dan seluruh peserta dapat mengikuti kegiatan dan berperan aktif dalam kegiatan. Setelah dilakukannya kegiatan ini, ilmu pengetahuan peserta bertambah khusunya mengenai back massage untuk membantu mempercepat penurunan tinggi fundus uteri setelah persalinan.
\end{abstract}

Kata kunci: pelayanan kesehatan, ibu postpartum, tinggi fundus uteri

\section{Abstract}

Health services for postpartum mothers need to be carried out in order to achieve optimal life for both mother and baby, one form of service to maximize the stability of the mother's mental health condition is to provide back massage intervention as an effort to prevent bleeding in postpartum mothers and accelerate the decrease in uterine fundal height. The purpose of community service is to provide information to postpartum mothers about Back Massage, as well as equip mothers with knowledge about back massage and teach this therapy to mothers to help accelerate the decrease in uterine fundal height after childbirth. This activity was carried out at the Marni Novera Midwife Independent Practice, Amd.Keb Padang, on Monday, July 12, 2021. The target of the activity was postpartum mothers at the Marni Novera Midwife Independent Practice, Amd.Keb. Overall, the activity was carried out according to the planned time and all participants were able to take part in the activity and play an active role in the activity. After this activity, the participants' knowledge increased, especially regarding Back Massage to help accelerate the decrease in uterine fundal height after childbirth.

Keywords: health services, postpartum mothers, uterine fundal height

Copyright (c) 2021 Titin Ifayanti, Silfina Indriani

$\triangle$ Corresponding author

Address : STIKes Alifah Padang

ISSN 2721- 9224 (Media Cetak)

Email : titin.titinifayanti@yahoo.com

ISSN 2721- 9216 (Media Online)

DOI : https://doi.org/10.31004/abdidas.v2i5.466 
1252 Edukasi Terapi Back Massage Terhadap Penurunan Tinggi Fundus Uteri Pada Kelas Ibu Hamil di Praktek Mandiri Bidan Marni Novera, Amd.Keb Padang - Titin Ifayanti, Silfina Indriani DOI: https://doi.org/10.31004/abdidas.v2i5.466

\section{PENDAHULUAN}

Periode postpartum merupakan masa transisi dimana terjadi perubahan secara fisik dan psikologis (Hutagaol, 2010; Pillitteri, 2010). Menurut Hasegawa (2009) banyak wanita mengalami depressive symptoms di hari pertama kelahiran. Hal ini dikarenakan pada hari pertama postpartum aktivitas saraf otonom dalam keadaan tidak stabil (Nakakita, 2011). Kondisi maternal depressive symptoms hanya sekitar $25 \%$ yang dilaporkan dan tertangani dengan baik pada tahun pertama postpartum (Norman et al., 2010; Klossner \& Hatfield, 2010).

Penyebab utama kematian ibu adalah perdarahan $28.5 \%$ yang dapat terjadi dalam persalinan maupun periode postpartum. Perdarahan periode postpartum yang diberikan sebagai perawatan postpartum untuk meransang keluarnya hormon oksitosin. Berdasarkan penelitian telah ditemukan bahwa terapi pijat Swedia dapat merangsang oksitosin (Beth et al., 2012).

Hormon oksitosin berguna untuk memperkuat dan mengatur kontraksi uterus, mengompresi pembuluh darah dan membantu hemostasis ibu sehingga mengurangi kejadian atonia uterus terutama pada persalinan lama. Kontraksi uterus yang kuat akan mengakibatkan proses involusi menjadi lebih bagus (Cunningham, 2006).

Oksitosin dapat diperoleh dengan berbagai cara baik melalui oral, intra-nasal, intra-muscular, maupun dengan pemijatan yang merangsang keluarnya hormon oksitosin. Sebagaimana yang ditulis Mark, Rapaport, Schettler, et al., (2012) dalam The Journal of Alternative And Complementary Medicine, bahwa dari data penelitian menunjukkan bahwa terapi pijat memiliki efek secara biologis, jika dilakukan 2 kali dalam 1(satu) minggu dengan sentuhan ringan mempunyai efek perubahan pada neuroendokrin yang dapat memicu pelepasan oksitosin dan dapat menjaga kesetabilan oksitosin. Oksitosin juga disintesis oleh neuron parvoselular dari paraventricular nucleus dari berbagai arah pusat sistem saraf termasuk saraf tulang belakang. Pada tulang belakang terdapat saluran yang dapat mengeluarkan oxytocinergic yang bertugas mengikat hormon oksitosin, pada lapisan permukaan dorsal horn daerah otonom (intermediolateral columns, intermediomedial greymatter, lamina $X$ dan sacral parasimpathetic nucleus) (Breton, 2008).

Pemijatan merupakan suatu intervensi yang efektif dan memiliki banyak manfaat. Intervensi pemijatan atau massage khususnya back massage dapat meningkatkan pelepasan hormon oksitosin dan meningkatkan relaksasi serta menurunkan kecemasan pada wanita postpartum. Manfaat back massage antara lain: merangsang pelepasan hormon oksitosin, mengurangi pembengkakan pada payudara, mengurangi sumbatan ASI, mempertahankan produksi ASI (Depkes RI, 2007 dalam Mardyaningsih, 2010; Modul WHO \& UNICEF, 2011).

Data penelitian yang menunjukkan bahwa back massage memiliki efek secara biologis, setelah dilakukan dengan pemijatan selama 2 kali 
dalam 1(satu) minggu dengan sentuhan ringan mempunyai efek perubahan pada neuroendokrin yang dapat memicu pelepasan dan menjaga kestabilan oksitosin (Mark etal., 2012).

Efek dari berbagai teknik relaksasi telah diperiksa. Secara khusus, pijat dikatakan untuk mengatur gangguan dalam tubuh karena rangsangan tekanan taktil ke kulit mempengaruhi tubuh, terutama sistem saraf otonom dan sistem endokrin (Koitabashi, Ohno, \& Kawauchi, 1994). Pada wanita pada fase awal nifas, efek psikologis dari pijatan punggung dilaporkan menyebabkan berkurangnya kecemasan dan peningkatan perasaan rileks (Imura, Misao, \& Ushijima, 2005; Nakakita \& Takenoue, 2009). Dengan demikian, pijatan yang diberikan kepada wanita di masa nifas dianggap efektif sebagai teknik perawatan relaksasi. Namun, dalam setiap penelitian dengan nifas seperti itu, efek relaksasi belum secara jelas dinilai dengan indikator fisiologis. Pemeriksaan efek fisiologis ini penting untuk perawatan nifas yang lebih baik.

Dilaporkan bahwa massage pada wanita di awal periode postpartum mampu mengurangi kecemasan dan meningkatkan relaksasi (Imura, Misao, \& Ushijima, 2005; Nakakita \& Takenou, 2009). Pemberian intervensi back massage pada masa postpartum menunjukkan penurunan depressive symptoms jika dibandingkan dengan perawatan standar (Shapiro, 2013).

Data penelitian menunjukkan bahwa terapi pijat memiliki efek secara biologis, setelah dilakukan dengan pemijatan selama 2 kali dalam 1(satu) minggu dengan sentuhan ringan mempunyai efek perubahan pada neuroendokrin yang dapat memicu pelepasan dan menjaga kestabilan oksitosin (Mark et al., 2012).

Pelayanan kesehatan bagi ibu postpartum perlu dilakukan guna mencapai kehidupan yang optimal baik ibu maupun bayinya, salah satu bentuk pelayanan untuk memaksimalkan kestabilan kondisi kesehatan mental ibu adalah dengan memberikan intervensi back massage sebagai upaya pencegahan terjadinya perdarahan pada ibu postpartum dan percepatan penurunan tinggi fundus uteri.

Berdasarkan fenomena diatas, penulis tertarik untuk melakukan pengabdian masyarakat tentang "Edukasi Therapi BackMassage terhadap penurunan tinggi fundus uteri pada kelas ibu hamildi Bidan Praktek Mandiri Padang Tahun 2021.

\section{METODE}

Kegiatan ini dilaksanakan di Praktek Mandiri Bidan Marni Novera, Amd.Keb Padang, pada hari Senin tanggal 12 Juli 2021. Sasaran kegiatan adalah ibu nifas yang ada di Praktek Mandiri Bidan Marni Novera, Amd.Keb. Adapun tujuan dari pengabdian masyarakat adalah untuk memberikan informasi kepada ibu nifas tentang Back Massage, serta membekali ibu derngan pengetahuan tentang back massage serta mengajarkan terapi ini kepada ibu untuk membantu mempercepat penurunan tinggi fundus uteri setelah persalinan. Metode kegiatan ini yaitu ceramah diskusi. Adapun tahap kegiatan yaitu 
1254 Edukasi Terapi Back Massage Terhadap Penurunan Tinggi Fundus Uteri Pada Kelas Ibu Hamil di Praktek Mandiri Bidan Marni Novera, Amd.Keb Padang - Titin Ifayanti, Silfina Indriani

DOI: https://doi.org/10.31004/abdidas.v2i5.466

tahap persiapan, pelaksanaan dan evaluasi kegiatan.

\section{HASIL DAN PEMBAHASAN}

\section{Persiapan}

Pada tahap ini diawali denganmeminta izin kepada Praktek Mandiri Bidan Marni Novera, Amd.Keb, dalam rangka pelaksanaan kegiatan pengabdian, menyampaikan maksud dan tujuan serta permohonan dukungan. Selain itu kegiatan ini juga melibatkan 2 mahasiswa kebidanan untuk dapat mengaplikasikan teori yang didapat dikampus kepada masyarakat. Hasil dari tahapan persiapan berupa diperkenankannya tim pengabdi untuk menyampaikan rencana kegiatan kepada masyarakat melalui kelas ibu hamil di PMB tersebut. Pertemuan pihak bidan, pihak ibu hamil dan tim pengabdian diawali dengan self assesment untuk menyamakan persepsi permasalahan yang ada di masyarakat, serta alternatif solusi.

\section{Pelaksanaan}

Kegiatan ini dilakukan pada hari Senin tanggal 12 Juli 2021 dengan jumlah peserta 20 orang. Tim pengabdian melakukan edukasi terapi back massage terhadap penurunan tinggi fundus uteri pada ibu nifas di Praktek Mandiri Bidan (PMB) Marni Novera, Amd.Keb Kota Padang. Kegiatan diawali dengan pemberian materi tentang back massage dan manfaatnya untuk ibu. Setelah penyampaian material, tim pengabdi melakukan sesi diskusi dan sesi tanya jawab dengan peserta. Baik tim pengabdi dan peserta mengikuti kegiatan ini dan kegiatan berjalan dengan lancar.

\section{Monitoring dan Evaluasi}

Pelaksanaan kegiatan berjalan dengan lancar. Selama kegiatan penyuluhan, peserta mendengarkan dengan seksama dan peserta antusias bertanya serta penyaji menjawab pertanyaan dari peserta. Secara keseluruhan kegiatan terlaksana sesuai dengan waktu yang direncankandan seluruh peserta dapat mengikuti kegiatan dan berperan aktif dalam kegiatan. Setelah dilakukannya kegiatan ini, ilmu pengetahuan peserta bertambah khusunya mengenai Back Massage untuk membantu mempercepat penurunan tinggi fundus uteri setelah persalinan.
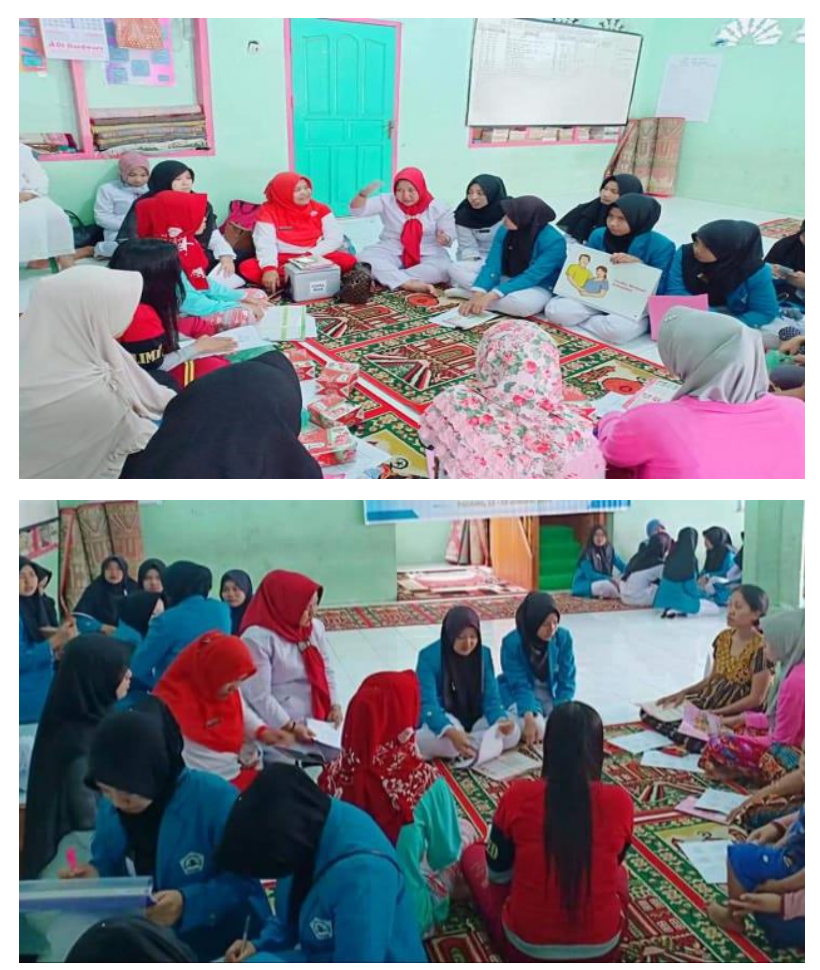

Gambar 1. Penyampaian Materi Kegiatan 


\section{SIMPULAN}

Tingginya minat masyarakat dalam mengikuti kegiatan pengabdian masyarakat melalui penyuluhan yang diselenggarakan dengan topik terapi back massage terhadap penurunan tinggi fundus uteri pada ibu nifas di Praktek Mandiri Bidan (PMB) Marni Novera, Amd.Keb Kota Padang. Diharapkan kepada ibu hamil agar dapat menerapkan pendidikan kesehatan yang telah diberikan tentang terapi back massage terhadap penurunan tinggi fundus uteri pada ibu nifas untuk dilakukan pada saat nanti setelah persalinan (masa nifas).

\section{DAFTAR PUSTAKA}

Azizah. Involution post partum mothers with a history of spontaneus labor complication when i-ii extend maternity room RSD Kalisat (thesis). Jember: Fakultas Ilmu Kesehatan. Universitas Muhammadiyah; 2013

Beth B., R.M.T, B.A, et al., (2013). Massage Benefits Immune and Neuroendocrine Function

.diakses melalui www.massagetoday.com. 02 September, 2014

Bintariadi, Bibin. 2007. Nifas Tinjauan Medis. www.nakita.com

Bobak I.M., Lowdermilk D.L., Jensen M.D., (2005). Buku Ajar Keperawatan Maternitas(Maternity Nursing) Edisi 4, Maria A Wijayarti dan Peter Anugerah (penterjemah).Jakarta: EGC.

Breton J.D., Veinante P., Bronner S.U., et al., (2008). Research Oxytocin InducedAntinocepcition In The Spnal Cord Is Mediated By A Subpopulation Of Glutamatergic Neurons In Lamina I-II Which Amplifi GABAergic Inhibition.BioMed Access. 1-12.
Cuningham FG, Leveno K, Bloom SL, Hauth C, Rause D, Spong CY. Obstetri Williams (terjemahan). Jakarta: EGC; 2012.

Depkes RI., (2007). Panduan Manajemen Laktasi : Diit Gizi Masyarakat. Jakarta: Depker RI.

Dharma K., (2011).Metodologi Penelitian Keperawatan (Panduan Melaksanakan dan

Menerapkan Hasil Penelitian). Jakarta: Trans Info Media.

Emily N, Margaret S, Richard H, Mary P. An exercise and education improves well-being of new mothers: a randomized controlled trial. American Physical Therapy Association. 2010; 90

Guyton A, Hall J. Buku ajar fisiologi kedokteran. Jakarta: EGC; 2007.

Hamranani S, (2010) Pengaruh Pijat Oksitosin Terhadap Involusi Uterus Pada Ibu PostPartum Dengan Persalinan Lama Di Rumah Sakit Wilayah Kabupaten Klaten.Tesis.Depok : Jakarta.

Larson M. Effect of postpartum exercise on mothers and their offspring: a review of the literature. Obesity research. 2002;10:841-53

Mardiyaningsih E., (2010). Efektifitas Kombinasi Teknik Marmet dan Pijat OksitosinTerhadap Produksi ASI Ibu Post partum Seksio Sesarea.Depok; Jakarta.

Mario C.P., (2004). Handbook Of Clinical Massage, A Complete Guide for Student andPractitioners. 2thEd. Churchil Livingstone: London.

Mark H., Rappaport M.D., Schettler P., PhD1., Bresee C, M.S2., (2012). A Pleminari Study OfThe Effects Of Repeated Massage On Hipothalamic-Pituitari-Adrenal And Immune Funtion In Healthy Individuals: A Study Of Mechanisms Of Action And Dosage, Thejournal of alternative and complementary medicine. 789-797.Murray R, Granner DK, Roodwell V. Biokimia Harper. Jakarta: EGC; 2009. hlm. 582-604.

Maryunani, Anik. (2009). Asuhan pada Ibudalam Masa Nifas. Jakarta: TIM 
1256 Edukasi Terapi Back Massage Terhadap Penurunan Tinggi Fundus Uteri Pada Kelas Ibu Hamil di Praktek Mandiri Bidan Marni Novera, Amd.Keb Padang - Titin Ifayanti, Silfina Indriani DOI: https://doi.org/10.31004/abdidas.v2i5.466

Notoatmodjo, Soekidjo. (2005).

MetodologiPenelitian Kesehatan. Jakarta:

PT.Rineka Cipta

Reeder,Martin, Kroniak-Griffin. (2011).

Keperawatan Maternitas:

KesehatanWanita,Bayi,\&Keluarga,Ed.18,Vol

.1.Jakarta: EGC

Simkin, Penny (2007). Panduan Lengkap Kehamilan Melahirkan dan Bayi. Jakarta: Arcan

Sugiyono. (2013). Statistik Untuk Penelitian. Bandung. Alfabeta.

Sulistyawati, Ari (2009). Buku Ajar Asuhan Kebidanan Pada Ibu Nifas. Jakarta. Salemba Medika. 